\title{
Will pollution taxes improve joint ecological and economic efficiency of thermal power industry in China? A DEA based materials balance approach
}

\author{
Ke Wang a,b,c,d,*, Zhifu Mi e, Yi-Ming Wei a,b,c,d \\ a Center for Energy and Environmental Policy Research \& School of Management and Economics, Beijing \\ Institute of Technology, Beijing 100081, China \\ b Sustainable Development Research Institute for Economy and Society of Beijing, Beijing 100081, China \\ c Beijing Key Lab of Energy Economics and Environmental Management, Beijing 100081, China \\ d Collaborative Innovation Center of Electric Vehicles in Beijing, Beijing 100081, China \\ e Bartlett School of Construction and Project Management, University College London, London WC1E 7HB, \\ UK
}

\begin{abstract}
Previous studies of the efficiency of Chinese electricity industry have been limited in providing insights regarding policy implications of inherent trade-offs of economic and environmental outcomes. This study proposes a modified data envelopment analysis method combined with materials balance principle to estimate ecological and cost efficiency in the Chinese electricity industry. The economic cost and ecological impact of energy input reallocation strategies for improving efficiency are identified. The possible impacts of pollution taxes upon the levels of sulfur dioxide $\left(\mathrm{SO}_{2}\right)$ emissions are assessed. Estimation results show that (i) both energy input costs and $\mathrm{SO}_{2}$ could be reduced through increasing technical efficiency. (ii) It is possible to adjust energy input mix to attain ecological efficient, and correspondingly, $\mathrm{SO}_{2}$ would reduce by $15 \%$. (iii) The Chinese electricity industry would reduce its unit cost by $9 \%$ if optimal ecological efficiency is attained and reduce its unit pollution by $13 \%$ if optimal cost efficiency is attained, implying that there are positive ecological synergy effects associated with energy cost savings and positive economic synergy effects associated with $\mathrm{SO}_{2}$ pollution reductions. (iv) Estimated shadow costs of $\mathrm{SO}_{2}$ reduction are very high, suggesting that, in the short term, the Chinese electricity industry should pursue cost efficient point instead of ecological efficient point, since alternative abatement activities are less costly and some of the abatement cost could be further offset by energy input cost savings. (v) There would be no significant difference between the impacts of pollution discharge fees and pollution taxes on $\mathrm{SO}_{2}$ emissions levels because of the relatively low pollution tax rate.
\end{abstract}

Keywords: Data envelopment analysis (DEA); Emission reduction; Energy efficiency; Environmental economics; Material balance; Sulfur dioxide $\left(\mathrm{SO}_{2}\right)$

\section{Introduction}

The emissions of $\mathrm{SO}_{2}$ derived from fossil fuel consumption are the major contribution to regional atmospheric contamination in China. This is more obvious in China's thermal power industry since it consumes approximate $45 \%$ of the total primary energy supply and contributes approximate $35 \%$ of $\mathrm{SO}_{2}$ emissions in China in 2014. Theoretically sound measurements of ecological and economic efficiency with appropriate measuring of pollution are critical for providing better information to assist policy making and industrial strategy decisions that result in better trade-offs on ecological and economic outcomes of not only the thermal power industry itself but the economic system as a whole (Wang and Wei, 2014; Liu et al., 2015; Halkos et al.,

* Corresponding author at Center for Energy and Environmental Policy Research, Beijing Institute of Technology, Beijing 100081, China. Tel: +86-10-68914938. E-mail: wangkebit@bit.edu.cn 
2016).

There have been numbers of non-parametric and parametric model based studies that address the economic and/or ecological efficiency evaluation for China's electricity industry. For instance, Lam and Shiu (2004) measured the total factor productivity (TFP) of China's thermal power generation without taking pollutions into accountant, and pointed out that technological change is the major driving force for TFP growth. Ma and Zhao (2015) estimated the operational efficiency of China's thermal power plants and their estimation showed that a large proportion of efficiency improvement is due to a number of technological mandates, and the unbundling reform also significantly improves the efficiency. Furthermore, with the consideration of effects of pollutant emissions (e.g., $\mathrm{NO}_{\mathrm{x}}$ and $\mathrm{SO}_{2}$ ), Yang and Pollitt (2010) estimated the environmental efficiency of China's coal-fired power plants. They showed that the average inefficiency is between $12-20 \%$, and the power plants wasted more input resources than their counterparts in US and Europe. Wei et al. (2013) estimated the environmental efficiency of China's power enterprises with the consideration of $\mathrm{CO}_{2}$ emissions and identified that the average inefficiency is between 6.1-18.9\%. Similar studies on efficiency measurement of China's electricity industry can be found in Lam and Shiu (2001), Yang and Pollitt (2009), Song et al. (2015), Du et al. (2016), and Wang et al. (2016a, 2017b).

The contributions of above studies are somewhat limited, since they mainly focused on improving technical and/or ecological efficiency through increasing economic outputs and/or reducing pollutions but paid less attention on improving allocative efficiency through adjusting inputs, especially pollution related energy inputs, and usually ignored to identify the economic cost (or benefit) and environmental impact of these strategies for improving efficiency. Therefore, they are likely to provide limited economic meanings and policy implications on the trade-offs of economic and environmental outputs, and they usually cannot estimate the economic and environmental consequences of these trade-offs in China's electricity industry. Few studies (e.g., Shi and Grafton, 2010; Shi, 2010) had decomposed efficiency measures into both technical efficiency and allocative efficiency; but they just focus on the coal mining industry in China. Wang et al. (2017a) examined the contribution of allocative efficiency in environmental efficiency in China's thermal power industry. However, only the allocation between polluting and nonpolluting inputs were examined; the allocation among different polluting inputs were not discussed.

Most of the existing studies had incorporated pollutions as byproducts of electricity generation into efficiency evaluation in various ways, such as (i) free disposable inputs (Hailu and Veeman, 2001; Picazo-Tadeo et al., 2005; Vázquez-Rowe et al., 2011; Masternak-Janus and RybaczewskaBłażejowska, 2017), (ii) weak disposable outputs (Färe et al., 1989; Molinos-Senante et al., 2014; Wang et al., 2016b), (iii) multiplicative inverse or additive inverse outputs (Sahoo et al., 2011; Seiford and Zhu, 2002), (iv) by-production traded outputs (Murty et al., 2012), and (v) natural/managerial disposability outputs (Sueyoshi and Goto 2012). However, these methods all have their specific limitations; see, e.g., Chen and Delmas (2012), Kuosmanen (2005) and Dakpo et al. (2016) for a discussion. One of these limitations is that the laws of thermodynamics are likely to be violated (Førsund, 2009; Hampf and Rødseth, 2015) and thus the above methods may result in inaccurate ecological efficiency measurement, especially when physical productivity is of concern and material/energy flows through industrial systems need to be quantified. It is actually very important when incorporating the energy related pollutions into efficiency measurement of thermal power industry (Welch and Barnum, 2009; Hampf, 2014), since the impacts of industrial activities (e.g., electricity generation) on the environment, the utilization of planet's supply of natural resources (e.g., fossil fuels), and the problems of pollution disposal (e.g., $\mathrm{SO}_{2}$ ) all need to be considered. 
In this study, we propose several modified joint ecological and economic efficiency evaluation models and associated efficiency measurements which are based on the materials balance principle (MBP) and in the form of non-radial DEA (Coelli et al., 2007; Welch and Barnum, 2009; Hampf and Rødseth, 2015) for efficiency measurement of China's thermal power industry so as to identify both the economic and ecological trade-offs inherent in electricity generation and to further assess the impact of pollutant discharge fees and potential pollution taxes upon the levels of $\mathrm{SO}_{2}$ emissions in this industry.

The primary contribution of this study is that it provides better understandings on allocation efficiency of energy inputs in electricity generation, considering both $\mathrm{SO}_{2}$ emissions and economic costs, which helps policy makers and managers to identify appropriate economic and ecological trade-offs, or in other words, provides them with information on how to balance economic costs and ecological benefits of $\mathrm{SO}_{2}$ emissions reduction in thermal power industry. Furthermore, this study provides an assessment of possible impact of the pollution taxation, which was recently released at the end of 2016 and is going to be enforced at the beginning of 2018 , on the levels of $\mathrm{SO}_{2}$ emissions and the costs of their reductions.

\section{Materials balance in economic analysis: a brief literature review}

The economic system where the production and consumption activities happen is embedded in the ecological system, and both of these systems are characterized by the flows of materials and energy which just can be converted from one form into another but the total amount remaining constant. This is known as the first law of thermodynamics or conservation laws of mass/energy, which states that materials and energy flows from and into environment are balanced (Lauwers, 2009). There have been quite a few literatures on integrating MBP or conservation laws of mass/energy into economics analysis which were built on the original works of Ayres and Kneese (1969), Kneese et al. (1970) and Noll and Trijonis (1971). They emphasized the importance of viewing environmental pollutions and their abatements as materials balance problems for the economic system. However, further economic modeling of the materials balance was rare and Pethig (2003) once pointed out that the MBP has been ignored since Ayres and Kneese (1969). Pethig (2003) argued that the neglect of MBP may cause biased economic analysis and result in flawed policy implication. In addition, Krysiak and Krysiak (2003) showed that most of the commonly applied economic modeling functions violate MBP which is caused by the inconsistency of different independent substitution processes introduced in the modeling. Explicitly and appropriately including the physical constraints in economic modeling helps to avoid the violation of MBP but will increase the complexity of the modeling process, which may be one reason that researchers were reluctant in including this principle (Färe et al., 2013). Therefore, Krysiak and Krysiak (2003) proposed a method for integrating MBP into static microeconomic modeling "with a minimum of changes" to the conventional modeling through using "effective prices" which consist of the price of a good corrected for the prices of its physically complementary goods. Pethig (2006) additionally proposed that the traditional production function with pollutions treated as inputs can be "reconstructed as a subsystem of a comprehensive production-cum-abatement technology" which is consistent with the MBP. Ebert and Welsch (2007) argued that Pethig (2006)'s technology is rather complicated and they proposed a different and simple approach with the MBP taking into account that the pollution can be treated as an input or a joint output, or can be described by a well-behaved emission function. They also proved that these three representations are equivalent.

Since the MBP based modeling helps to connect economic and environmental analysis, it has been recently directly used in ecological economic modeling. For instance, Vatn (1998) showed 
the advantages of a material flow perspective in environmental economic analysis and based on which he provided a measure of trade-off between the precision of an environmental regulation and its implementation costs. Bringezu et al. (2003) developed indicators based on economywide material flow analysis to evaluate and monitor the metabolic performance of economies. Ščasný ey al. (2003) derived indicators on the basis of accounts and balances of material flows and applied them for examining the decoupling of economic growth from environmental pressure in Czech. Pérez-Rincón (2006) provided a material flow analysis of the relations between trade, economy and the environment in Colombia for identifying its unequal monetary and ecological exchanges. Through employing MBP and endogenous growth method, Akao and Managi (2007), provided a feasibility and optimality condition for sustainable growth that balance the economy and environmental quality.

As pointed out by Hoang and Rao (2010), The MBP adjusted environmental efficiency measures may suffer two limitations. The first one is the ambiguity in treating non-material inputs and the different types if energy inputs, while the second one is the lack of widely accepted weights for the integration of various types of material/energy inputs. The introducing of cumulative exergy content helps to overcome this problem (Ayres, 1998) since the concept of exergy is a good physical common unit of various material/energy inputs, and it can be used to capture the real economics significance of the second law of thermodynamics that exergy is not conserved. Based on the cumulative exergy, Hoang and Rao (2010) developed new technical efficiency and exergy allocative efficiency measures and applied them in agricultural production in OECD countries. Recently, Kuosmanen and Kuosmanen (2013) argued that static MBP ignores an important feature of material cycle: pollutions may cause delayed effects and persistent harm to environment. Therefore, they proposed a dynamic method of MBP to estimate both the flows and the stocks of materials (nitrogen) in environment, and applied this method in agricultural production in Finland and other European countries (Kuosmanen, 2014) so as to provide insights for policy advices from a dynamic perspective.

\section{Materials balance conditions and ecological efficiency measurement}

Introduced and further developed in Ayres and Kneese (1969), Coelli et al. (2007) and Rødseth (2016, 2017), the MBP method is considered more tightly linked to economic modelling for efficiency and productivity than most of other DEA models in dealing with undesirable outputs, especially when physical laws and costs of both economic production and pollutant discharge are of concern in measurement. To place the MBP adjusted production efficiency and productivity method in an applied ecological economics context has the advantage of bridging the gap between the conventional economics efficiency analysis and ecological efficiency analysis, and consequently, making the economic and ecological outcomes equally explicit in analysis.

The MBP states that the total amount of mass (e.g., sulfur) in the polluting inputs (e.g., coal) should equal the mass in desirable outputs (e.g., calcium sulfate as building material) plus the mass in the residuals that cause pollution (e.g., $\mathrm{SO}_{2}$ emissions). The MBP is defined as:

$\alpha e-\beta y=b+a$

in which $\boldsymbol{e}, \boldsymbol{y}$ and $\boldsymbol{b}$ represent the vectors of inputs, desirable outputs and emitted pollutions; $\boldsymbol{a}$ is a vector of abatements of pollutions; $\boldsymbol{\alpha}$ and $\boldsymbol{\beta}$ are the vectors of unit mass in the inputs (emission factors) and the vectors of unit mass in the desirable outputs (recuperation factors). Note that, the component of $\boldsymbol{\alpha}$ related to the non-polluting input is zero; the component of $\boldsymbol{\beta}$ is zero for the desirable output containing non-polluting mass. We assume $\boldsymbol{a}=0$ if there is no abatement on 
pollutions or $\boldsymbol{b}$ represents the produced pollutions instead of the emitted pollutions; otherwise we set $\boldsymbol{a}>0$.

Suppose there is a sample of $n$ firms having desirable outputs, non-polluting (non-energy) inputs, polluting (energy) inputs, and produced (not discharged) undesirable outputs (pollutions) denoted by $\left(y_{r j}, x_{i j}, e_{i j}, b_{i j}\right)$, where $i=1, \ldots, m_{1}$ (for $x$ ), $i=m_{1}+1, \ldots, m$ (for $e$ and $b$ ), $r=1, \ldots, s$, and $j=1, \ldots, n$. In this study, we propose three DEA based MBP methods for efficiency measurement in which $\theta^{T}$, $\theta_{i}^{E}$ and $\theta_{i}^{C}$ are variable for adjusting energy inputs and associated pollution outputs, $d_{r j}^{(\cdot) y}, d_{i j}^{(\cdot) x}, d_{i j}^{(\cdot) e}$ and $d_{i j}^{(\cdot) b}$ are slack variables implementing weak G-disposability for the MBP (see Supplementary for details of three DEA models).

Next, we come to the definitions of efficiency measurements. First, ecological efficiency ( $E E$ ) is measured as the ratio of minimal pollutions over observed pollutions, which takes the value between 0 and 1, with the value 1 denoting full ecological efficiency.

Ecological efficiency $(E E)=\frac{\sum_{i=m_{1}+1}^{m} \alpha_{i j}\left(\theta_{i}^{E} e_{i j}-d_{i j}^{E e}\right)}{\sum_{i=m_{1}+1}^{m} \alpha_{i j} e_{i j}}, j=1, \ldots, n$

$E E=1$ indicates that, using current technology, there is no possibility to produce current amount of desirable output with a lower pollution. $E E$ can be decomposed into two components as ecological technical efficiency (ETE) and ecological allocative efficiency $(E A E)$ :

Ecological technical efficiency $(E T E)=\frac{\sum_{i=m_{1}+1}^{m} \alpha_{i j}\left(\theta^{T} e_{i j}-d_{i j}^{T e}\right)}{\sum_{i=m_{1}+1}^{m} \alpha_{i j} e_{i j}}, j=1, \ldots, n$

Ecological allocative efficiency $(E A E)=\frac{\sum_{i=m_{1}+1}^{m} \alpha_{i j}\left(\theta_{i}^{E} e_{i j}-d_{i j}^{E e}\right)}{\sum_{i=m_{1}+1}^{m} \alpha_{i j}\left(\theta^{T} e_{i j}-d_{i j}^{T e}\right)}, j=1, \ldots, n$

$E T E$ measures the distance a firm to be projected onto production frontier, while $E A E$ measures the correctness on energy input mix of a firm. ETE and $E A E$ both take value between 0 and 1, and value 1 indicates full efficiency. There exists a relationship among the above three ecological efficiency measurements: $E E=E T E \times E A E$.

Second, if we take the information on energy input prices $\left(p_{i j}\right)$ into consideration and replace the emission factors in equations (2) to (4) with the price levels, and follow a similar procedure, we could get the measurements of cost efficiency $(C E)$ and its decompositions of cost allocative efficiency $(C A E)$ and cost technical efficiency $(C T E)$ :

Cost efficiency $(C E)=\frac{\sum_{i=m_{1}+1}^{m} p_{i j}\left(\theta_{i}^{C} e_{i j}-d_{i j}^{C e}\right)}{\sum_{i=m_{1}+1}^{m} p_{i j} e_{i j}}, j=1, \ldots, n$

Cost technical efficiency $(C T E)=\frac{\sum_{i=m_{1}+1}^{m} p_{i j}\left(\theta^{T} e_{i j}-d_{i j}^{T e}\right)}{\sum_{i=m_{1}+1}^{m} p_{i j} e_{i j}}, j=1, \ldots, n$

Cost allocative efficiency $(C A E)=\frac{\sum_{i=m_{1}+1}^{m} p_{i j}\left(\theta_{i}^{C} e_{i j}-d_{i j}^{C e}\right)}{\sum_{i=m_{1}+1}^{m} p_{i j}\left(\theta^{T} e_{i j}-d_{i j}^{T e}\right)}, j=1, \ldots, n$

Similarly, these three measures are related as $C E=C T E \times C A E$.

The measurement of ecological efficiency helps a firm $j$ to identify the energy related pollution minimizing point where the corresponding pollution is $\alpha_{i j}\left(\theta_{i}^{E} e_{i j}-d_{i j}^{E e}\right)$, while the measurement of cost efficiency helps this firm to identify the energy input cost minimizing point where the corresponding cost is $p_{i j}\left(\theta_{i}^{C} e_{i j}-d_{i j}^{C e}\right)$. In addition, we could also identify two additional values: the cost corresponding to the pollution minimizing point, $p_{i j}\left(\theta_{i}^{E} e_{i j}-d_{i j}^{E e}\right)$, and the pollution corresponding to the cost minimizing point, $\alpha_{i j}\left(\theta_{i}^{C} e_{i j}-d_{i j}^{C e}\right)$. Then, for the $i$ th 
pollution of the $j$ th firm, the cost associated with shifting from the cost minimizing point to the pollution minimizing point can be identified through the concept of shadow cost (SC) of pollution reduction: $p_{i j}\left(\theta_{i}^{E} e_{i j}-d_{i j}^{E e}\right)-p_{i j}\left(\theta_{i}^{C} e_{i j}-d_{i j}^{C e}\right)$. In addition, the pollution associated with shifting from the pollution minimizing point to the cost minimizing point can be identified by using shadow pollution (SP) of cost reduction: $\alpha_{i j}\left(\theta_{i}^{C} e_{i j}-d_{i j}^{C e}\right)-\alpha_{i j}\left(\theta_{i}^{E} e_{i j}-d_{i j}^{E e}\right)$.

In the above definition and discussion, only the prices of energy inputs are included, if the prices of pollutions, e.g., pollution discharge fees or pollution taxes, are available, then these prices can be used to identify a new optimal point of cost minimizing. In this case, both the economic cost of energy input and the social cost of energy related pollution, which is (partially) represented by pollution fee or tax, are taken into account, and thus we could name this new optimal point as "total" cost minimizing point and the corresponding efficiency measurement as total cost efficiency (TCE). Similarly, we have TCE = total cost technical efficiency $(T C T E) \times$ total cost allocative efficiency (TCAE). Suppose the rate of pollution fee or tax is denoted by $u_{i j}$, we could obtain the new "total" price $p_{i j}^{T}$, which is composed of unit price of energy input and pollution fee rate (i.e., unit price of pollution) as $p_{i j}^{T}=p_{i j}+\alpha_{i j} u_{i j}$. Then, the corresponding total cost minimizing point switches from $p_{i j}\left(\theta_{i}^{C} e_{i j}-d_{i j}^{C e}\right)$ to $p_{i j}^{T}\left(\theta_{i}^{C} e_{i j}-d_{i j}^{C e}\right)=\left(p_{i j}+\alpha_{i j} u_{i j}\right)$. $\left(\theta_{i}^{C} e_{i j}-d_{i j}^{C e}\right)=p_{i j}\left(\theta_{i}^{C} e_{i j}-d_{i j}^{C e}\right)+u_{i j}\left(\theta_{i}^{C} b_{i j_{0}}-d_{i j}^{C b}\right)$, which indicates that the price of energy input is adjusted by a multiplier of emission factor of pollution and price of pollution. This framework could be applied to assess the impact of pollution discharge fees or pollution taxes upon the status of ecological efficiency of firms and the levels of pollution in industries.

\section{Dataset for efficiency measurement}

The panel dataset we used contains 93 China's provincial thermal power industry sectors operating in the period of 2011 (23 sectors), 2012 (22 sectors), 2013 (24 sectors) and 2014 (24 sectors). We model the technology set of thermal electricity generation and associated $\mathrm{SO}_{2}$ emissions with three energy inputs: the consumption of coal, natural gas, and oil ${ }^{1}$; two nonenergy inputs: the installed capacity and employed staff; one economic output: electricity generation; and one pollution output: $\mathrm{SO}_{2}$ emissions from the combustion of coal, oil and natural gas. In addition, the $\mathrm{SO}_{2}$ emission factors and prices of coal, natural gas, and oil are included in our evaluation. The data on energy consumption are collected from the energy balance table (the subsector of "thermal power" within the "input and output of transformation" sector) in China's energy statistical yearbooks; the information on installed capacity and electricity generation are collected from China's electricity statistical yearbooks; the employee data are collected from China's industrial statistical yearbooks; and the data on $\mathrm{SO}_{2}$ emissions are collected from China's environmental statistical yearbooks. The emission factors are estimated according to China's Material Balance Standard for Fuel Combustion Related Air pollutants and adjusted according to the observed emissions of different regional sectors, while the information on all energy prices are obtained from reports of China's National Development and Reform Commission and WindData. Supplementary table 1 to 3 respectively report the summary statistics of input and output data, provincial specific $\mathrm{SO}_{2}$ emission factors, and current $\mathrm{SO}_{2}$ discharge fee rate and planned $\mathrm{SO}_{2}$ pollution tax rate.

\section{Ecological and cost efficiency of China's thermal power industry}

The evaluation results on $E E$ and $C E$ are summarized in Table $1^{2}$. For China's thermal power industry during 2011-2014, the mean EE score is 0.8635 indicating that the average thermal 
power industry sector should be able to generate its current electricity with an energy input mix that contains $13.65 \%$ less sulfur. The mean ETE and EAE scores are 0.9111 and 0.9498 , respectively, which suggest that the average sector should have the ability to generate its current electricity with 8.89\% fewer energy input through technical efficiency improvement and with $5.02 \%$ fewer energy input through adjusting its current sub-optimal energy mix. The mean TCE score is 0.8453 indicating that the average sector could reduce its energy input cost by $15.47 \%$ while maintaining its current electricity generation. The total cost inefficiency is due to both the technical inefficiency and allocative inefficiency. The mean TCAE of 0.9300 suggests that the average sector is using an energy input mix that is $7.00 \%$ away from the cost minimizing energy input $\mathrm{mix}^{3}$. Note that the differences between the means of $C E$ and TCE, and their decomposed counterparts, are very small. That is because the current $\mathrm{SO}_{2}$ pollutant discharge fee rates are quite low compared with the energy prices, which makes the total prices of energy inputs quite close to their market price. Thus, we just focus on TCE in the following sections.

\section{[Insert Table 1 here]}

The above (in)efficiency measurements are all presented in percentage forms and we consider that the total values on energy savings and $\mathrm{SO}_{2}$ reductions would also be noteworthy. Table 2 reports the possible value changes on energy inputs and $\mathrm{SO}_{2}$ emissions associated with efficiency changes which are all annually average values. Given that the evaluated provincial thermal power industry sectors are representative of the population (provincial regions having two typical types of thermal power industry, i.e., coal- and natural gas-fired power plants that above state designated scale, are included), we could make the following estimations ${ }^{4}$. Table 2 shows that China's thermal power industry sector would reduce 103 million t of coal (6.6\%), 909 thousand $\mathrm{t}$ of oil $(36.2 \%)$, and 1754 million $\mathrm{m}^{3}$ of natural gas $(8.5 \%)$ annually but keep its electricity generation unchanged if it was technical efficient. Correspondingly, the $\mathrm{SO}_{2}$ emissions from this sector would reduce $421,133 \mathrm{t}$ which accounts for $7.8 \%$ of its annual total $\mathrm{SO}_{2}$ emissions.

\section{[Insert Table 2 here]}

Similarly, this industry sector would reduce 239 million tonnes of coal and 79,000 tonnes of oil, while increase 18,102 million $\mathrm{m}^{3}$ of natural gas annually to generate the same electricity if it was ecological efficient. This is an interesting and powerful implication that China's thermal power industry is possible to reduce its $\mathrm{SO}_{2}$ emissions by $15.2 \%(818,339 \mathrm{t})$ annually through adjusting its energy input mix, i.e., reducing coal and oil input by $15.3 \%$ and $3.1 \%$, respectively, and, as a compensation, increasing natural gas input by $87.9 \%$. In fact, this implication is in line with China's energy development strategies of $12^{\text {th }}$ and $13^{\text {th }}$ Five-Year-Plan periods that the proportion of coal consumption in total primary energy consumption should reduce to $58 \%$ by 2020 , while the proportion of natural gas consumption should increase to $10 \%$ by 2020 , respectively. And more specifically, China's development strategy for electricity industry plans to increase its capacity of gas-fired power generation from 60 million kw (2015) to 110 million kw (2020) indicating a significant $83.3 \%$ increase. Our estimation actually provides another support for this ambitious growth target.

In addition, it can be seen that there would be annually 180 million tonnes (11.5\%), 1,009 thousand tonnes $(40.1 \%)$, and 8,604 million $\mathrm{m}^{3}(41.8 \%)$ reduction potentials on coal, oil, and natural gas, respectively, if the cost inefficiency in this industry was eliminated. Then, the corresponding $\mathrm{SO}_{2}$ emissions would decrease by $13.2 \%(709,859 \mathrm{t})$. This result indicates that to approach the energy input cost minimizing point through adjusting the current energy input mix 
to the optimal mix would help China's thermal power industry to reduce all three types of its energy inputs and the associated $\mathrm{SO}_{2}$ emissions substantially.

Note in the tenth and the last rows of Table 2, there would be additional 397,207 or 288,727 tonnes $(8.0 \%$ or $5.8 \%) \mathrm{SO}_{2}$ emissions reductions if this industry sector keeps moving along the technical efficiency frontier until reaching the sulfur pollution minimizing point or the energy cost minimizing point. The technical efficiency sectors can generate electricity on different points on the technical efficiency frontier, while the ecological efficient or cost efficient sectors must be on a specific point with minimum pollution or a specific point with minimal cost. The distance between the technical efficient point and the ecological efficient point or cost efficient point leads to the above additional $\mathrm{SO}_{2}$ emissions reduction potentials.

One more interesting result is that improving $T E$ would both reduce $\mathrm{SO}_{2}$ emissions and reduce energy costs, but improving $E A E$ (and thus reducing $\mathrm{SO}_{2}$ ) may result in increased energy cost in some cases. For instance, as shown in the sixth to the eighth rows of Table 2, an $87.9 \%$ increase on natural gas is suggested so as to (partially) compensate for the $15.3 \%$ reduction on coal, which is likely to result in an increase in energy cost, since the relative price of natural gas (approximate 90 Yuan/million kJ) is much higher than coal (approximate 26 Yuan/million kJ) in China in 2014. Therefore, improving EE may lead some thermal power sectors moving away from the energy cost minimizing point, i.e., there might be costs associated with generating electricity on the pollution minimizing point for some sectors, and thus there would be economic and ecological trade-offs inherent in electricity generation. We will further discuss this issue.

\section{Ecological and economic trade-offs in China's thermal power industry}

We estimate the changes on the four year's average energy input cost per unit electricity generation and $\mathrm{SO}_{2}$ emissions per unity electricity generation for each regional thermal power industry sector which are shown in Tables 3 and 4, respectively. The last rows in these tables provide the mean values of China. It can be seen that the average sector would reduce per unit electricity generation cost by $9.1 \%$ if it operated on the technical efficiency frontier, and would reduce this cost by $14.3 \%$ if it was cost efficient. Similarly, one can see that the average sector would reduce per unit electricity generation pollution by $10.0 \%$ if it was technical efficient, and would reduce this pollution by $14.6 \%$ if it operated on the ecological efficient point. These percentage reductions are very important since they suggest that if the thermal power industry were able to utilize the current available generation technology efficiently, then both its electricity generation cost and pollution would reduce by approximate $9-10 \%$ which is indeed a substantial amount. Under such circumstance, there will be no need for implementing extra and expensive pollution reduction technologies, such as end-of-pipe $\mathrm{SO}_{2}$ scrubber, in the short term, and in addition, in the middle and long term, some of the extra expense on pollution reduction could be offset by the electricity generation cost savings.

\section{[Insert Tables 3 and 4 here]}

As shown in Tables 3 and 4, it is interesting that the average sector would also reduce per unit electricity generation cost by $9.3 \%$ if it was ecological efficient, and would reduce this cost by $0.3 \%$ if it continued to move along the technical efficiency frontier until reaching the pollution minimizing point. Furthermore, the average sector also would reduce per unit electricity generation pollution by $12.9 \%$ if attained cost efficient, and would reduce this pollution by $3.2 \%$ if it continued to move along the technical efficiency frontier until reaching the cost minimizing point. These percentage reductions are extremely important which imply that, on average, this 
industry could, on the one hand, decrease electricity generation cost by attaining the ecological efficient point, and on the other hand, decrease electricity generation pollution by approaching the cost efficient point. In other words, for this industry as a whole, there is no extra cost on pollution reduction through ecological efficiency improvement, and there is no extra pollution on cost reduction through cost efficiency increase. These positive ecological (or economic) synergy effects associated with energy input cost savings (or $\mathrm{SO}_{2}$ pollution reductions) identified in this study provide another support to China's current efforts on energy conservation and emissions reduction in industry, especially its thermal power industry sector.

Next, we provide an analysis of the ecological and economic trade-offs focusing on individual thermal power industry sectors at the provincial level instead of at the national average level, since what is true in general for the industry is usually not true for its specific regional sectors. Furthermore, such analysis is worthwhile for determining what adjustments on energy input mix would be necessary for those inefficient regional sectors to improve their efficiency to the levels of their benchmark regional sectors.

It can be found in Tables 3 and 4 that, firstly, the thermal power industry sectors in three regions are technical efficient (code 1, $7 \& 10$ ), in which sectors code 1 and 7 are ecological efficient but do not have the highest generation cost per unit electricity; while sector code 10 is cost efficient but does not have the highest $\mathrm{SO}_{2}$ emissions per unit electricity. This result implies that performing best on one object (e.g., having the highest ecological efficiency score or cost efficiency score), does not necessarily mean that this thermal power industry sector would performing worst on other objects (such as having the highest unit cost of energy input or unit sulfur mass bounded in energy input).

Secondly, note that the thermal power industry sectors in four regions are technical efficient (code 4, 17, 18 \& 19), however, they are neither ecological efficient nor cost efficient. Taking regional sector code 18 as an example, if it attained full ecological efficiency it would reduce its $\mathrm{SO}_{2}$ emissions per unit electricity by $8.4 \%$ as shown in Table 4 , and, simultaneously, it would reduce its generation cost per unit electricity by $9.0 \%$ as shown in Table 3 . On the other hand, this regional sector would reduce its generation cost per unit electricity by $25.2 \%$ if it attained full cost efficiency as shown in Table 3 , but in the meantime, it would increase its $\mathrm{SO}_{2}$ emissions per unit electricity by $0.8 \%$ as shown in Table 4 . This result indicates that there would be a positive synergy effect on cost efficiency improvement for regional sector code 18 when it approaching ecological efficient point; while there would be no such positive synergy effect in the opposite way. Thus, this regional sector is suggested to primarily focus on improving its ecological efficiency. For the remaining three regional sectors (code 4, 17 \& 19), they are suggested to either improving ecological efficiency or improving cost efficiency, since each of these two ways would have positive synergy effect on the other one. In other words, these technical efficient sectors could improve both cost and ecological efficiency simultaneously by moving towards either cost or pollution minimizing points along the technical efficiency frontier.

Thirdly, in fact, most of the technical inefficient regional thermal power industry sectors (16 of the 25 sectors) could improve both cost and ecological efficiency through moving towards the pollution minimizing points, and most of the technical inefficient regional thermal power industry sectors (18 of the 25 sectors) could improve both ecological and cost efficiency through moving towards the cost minimizing points.

Fourthly, note that, since each regional thermal power industry sector has its own energy input prices and $\mathrm{SO}_{2}$ emissions factors, the cost or pollution minimizing points, which are the points of tangency between technical efficiency frontier and iso-cost line or iso-pollution line, are unique for a specific regional sector. This means that each sector would have specific ecological and 
economic trade-offs. This can be seen from the variety of percentages presented in the last two columns in Tables 3 and 4. There is an interesting implication that it is possible to identify specific regional thermal power industry sectors (code 19, $21 \& 22$ ) that each has overlapped cost efficient and ecological efficient points, i.e., these sectors could simultaneously attain full cost efficiency and full ecological efficiency.

Fifthly, Table 3 shows that regional thermal power industry sector code 25 has the lowest generation cost per unit electricity of 0.256 Yuan $/ \mathrm{kWh}$. However, it is neither ecological efficient nor cost efficient. On the one hand, to achieve ecological efficient point, it must reduce its $\mathrm{SO}_{2}$ emissions per unit electricity by $22.2 \%$ and would reduce its generation cost per unit electricity by $23.9 \%$. On the other hand, to attain cost efficient, it must reduce its generation cost per unit electricity by $25.2 \%$ and would reduce its $\mathrm{SO}_{2}$ emissions per unit electricity by $21.5 \%$. Table 4 shows that regional thermal power industry sector code 1 has the smallest $\mathrm{SO}_{2}$ emissions per unit electricity of $0.346 \mathrm{~g} / \mathrm{kWh}$, and it is both technical efficient and ecological efficient. However, it is not cost efficient. To reach cost efficient point, it would reduce its generation cost per unit electricity by $19.8 \%$ but must increase its $\mathrm{SO}_{2}$ emissions per unit electricity by $71.9 \%$.

Finally, we come to the estimations of shadow cost (SC) and shadow pollution (SP). Table 5 gives the $\mathrm{SC}$ of $\mathrm{SO}_{2}$ emissions reduction and the SP of energy input cost reduction. The 3rd column shows total SC of each regional sector for moving from its cost minimizing point to pollution minimizing point; the 4th and 5th columns show the SC per unit electricity and its proportion in unit electricity generation cost. In addition, the 6th to 8th columns respectively shows the SP, SP per unit electricity and its proportion in unit electricity generation emission. It can be found that regional sector code 1 has both the highest proportion of unit SC in unit electricity generation cost (22.2\%) and the largest proportion of unit SP in unit electricity generation emission (71.9\%). The last column shows the unit SC per $\mathrm{kg} \mathrm{SO}_{2}$ emissions reduction of each regional sector and the average sector. Note that, regional sector code 12 has the highest unit $\mathrm{SC}$ for $\mathrm{SO}_{2}$ emissions reduction (2.72 Yuan/g), while regional sector code 21 shows the lowest one (0.03 Yuan/g). The average shadow cost of $\mathrm{SO}_{2}$ emissions reduction in China's thermal power industry is 571 Yuan/kg. This cost is much higher than the current abatement cost of $\mathrm{SO}_{2}$ in representative coalfired power plant in China, which is approximate 3.8-4.4 Yuan/kg without taking into account the benefit from flue gas desulfurization gypsum production and subsidy on electrovalence. This result provides one important implication that, in general, China's thermal power industry is suggested to adjust the energy input mix so as to approach the cost minimizing point instead of attempting to move further to the pollution minimizing point, since the alternative $\mathrm{SO}_{2}$ abatement activities, such as flue gas desulfurization are much less costly, and in addition, some of the abatement cost could be further offset by energy input cost savings, gypsum productions, electrovalence subsidies, and pollutant discharge fee savings. However, we should also notice that there are several regional thermal power industry sectors have relative low unit $\mathrm{SC}$ of $\mathrm{SO}_{2}$ emissions reduction, such as regional sectors code 7, 20 and 21 whose unit SCs are between 32 36 Yuan $/ \mathrm{kg}$. Moving further towards the pollution minimizing point to a certain extent is still acceptable for these sectors, since the end-of-pipe $\mathrm{SO}_{2}$ abatement expense, especially the labor cost, in specific regional sector (e.g., code 7) is likely much higher than China's average level.

\section{[Insert Table 5 here]}

\section{Environmental impacts of potential pollution taxes on China's thermal power industry}

On December $25^{\text {th }}, 2016$, a new environmental protection taxation law was passed and issued by China's supreme legislative institution which will be enforced since January $1^{\text {st }}, 2018$. Then, the 
mechanism of pollutant discharge fee that has been implemented for more than 30 years in China will be fully replaced by an environmental taxation. As reported in Supplementary table 3, the lower bounds of the $\mathrm{SO}_{2}$ pollution tax rate in different regions are various, ranging in 1.26-10.00 Yuan/kg; while the upper bound are identical of 12.63 Yuan $/ \mathrm{kg}$.

We assess the impact of these two pollution taxes scenarios on electricity generation cost and $\mathrm{SO}_{2}$ emissions, and the results for the average sector are presented in Table 6. The 2nd and 3rd rows show the observed generation cost (the electrovalence subsidies on desulfurization are included) and $\mathrm{SO}_{2}$ emissions per unit electricity under the current $\mathrm{SO}_{2}$ discharge fee mechanism; the 4 th and 5th rows show the above two values if the average sector would generate at the cost efficient point; and the 6th row shows the unit shadow cost of the average sector. The 7 th and 11th rows report the estimated generation costs per unit electricity if the $\mathrm{SO}_{2}$ discharge fee is replaced by the $\mathrm{SO}_{2}$ pollution tax with lower bound rate or upper bound rate, which indicate that the unit cost at the cost efficient point would increase from 0.330 to 0.331 and 0.349 Yuan/kWh. Correspondingly, $\mathrm{SO}_{2}$ emissions per unit electricity at the cost efficient point would change. The percentages in the 8 th and 12 th rows indicate that, compared with the current $\mathrm{SO}_{2}$ discharge fee mechanism, the unit cost would slightly increase by $0.49 \%$ and $5.70 \%$ within the lower and upper bound of $\mathrm{SO}_{2}$ pollution tax scenarios, respectively; while the percentages in the 9th and 13th rows indicate that, at the same time, the unit $\mathrm{SO}_{2}$ emissions would slightly decrease by $0.0003 \%$ and $0.0155 \%$ within the lower and upper bound of $\mathrm{SO}_{2}$ pollution tax scenarios, respectively. Furthermore, the shadow cost per unit $\mathrm{SO}_{2}$ would change from 0.571 to 0.569 and 0.564 Yuan/g within the $\mathrm{SO}_{2}$ pollution tax scenarios, as shown in the 10 th and last rows.

\section{[Insert Table 6 here]}

Most of the changes identified are tiny indicating that there will be no significant difference between the impacts of pollution discharge fees and pollution taxes on pollution levels for the thermal power industry. This result is not surprising since, compared with the energy input prices, even the upper bound of $\mathrm{SO}_{2}$ pollution tax rate are very low which is not likely to significantly influence the energy mix adjustment and pollution abatement strategies. However, we must recognize that the planned pollution taxation mechanism (national legislation) has higher priority than the current pollution discharge fee mechanism (regional legislation) and thus the former will be enforced more strictly than the latter, which guarantees the $\mathrm{SO}_{2}$ abatement performance of the pollution taxes.

\section{Conclusion}

This study estimates the ecological and cost efficiency of thermal power industry in China and identifies economic and ecological trade-offs inherent in electricity generation. The impacts of pollutant discharge fees and potential pollution taxes upon the levels of $\mathrm{SO}_{2}$ emissions are assessed. Our findings provide policy makers and managers with information on how to balance the economic costs and ecological benefits of $\mathrm{SO}_{2}$ emissions reduction. One could utilize the information as reference for setting appropriate level of pollution tax (on worse polluting energy inputs such as high-sulfur coal) or pollution reduction subsidy (on less polluting energy inputs like natural gas) so as to stimulate this industry to adjust its energy input mix for cost-effectively reducing pollutions. Further analysis may additionally take into account other major air pollutions, which may provide us the possibility for identifying the ecological synergy effects of multi-pollution control strategies. 


\section{Acknowledgements}

We gratefully acknowledge the supports from National Natural Science Foundation of China (Nos. 71471018, 71521002, 71642004), Social Science Foundation of Beijing (No. 16JDGLB013), Joint Development Program of Beijing Municipal Commission of Education, National Key R\&D Program (No. 2016YFA0602603), and Science and Technology Project of State Grid Corporation Headquarters (No. YD71-16-014). Wang K. is grateful to the supports of Key Technology Partnership (KTP) Visiting Fellow Program from UTS and BIT and International Clean Energy Talent Program (2017) from Chinese Scholarship Council (No. 201702660030).

\section{References}

Akao, K. I., \& Managi, S. (2007). Feasibility and optimality of sustainable growth under materials balance. Journal of Economic Dynamics and Control, 31(12), 3778-3790.

Ayres, R. U. (1998). Eco-thermodynamics: economics and the second law. Ecological economics, 26(2), 189-209.

Ayres, R. U., \& Kneese, A. V. (1969). Production, Consumption, and Externalities. The American Economic Review, 59(3), 282-297.

Bringezu, S., Schütz, H., \& Moll, S. (2003). Rationale for and interpretation of economy-wide materials flow analysis and derived indicators. Journal of Industrial Ecology, 7(2), 43-64.

Chen, C. M., \& Delmas, M. A. (2012). Measuring eco-inefficiency: a new frontier approach. Operations Research, 60(5), 1064-1079.

Coelli, T., Lauwers, L., \& Van Huylenbroeck, G. (2007). Environmental efficiency measurement and the materials balance condition. Journal of Productivity Analysis, 28(1-2), 3-12.

Dakpo, K. H., Jeanneaux, P., \& Latruffe, L. (2016). Modelling pollution-generating technologies in performance benchmarking: Recent developments, limits and future prospects in the nonparametric framework. European Journal of Operational Research, 250(2), 347-359.

Du, L., Hanley, A., \& Zhang, N. (2016). Environmental technical efficiency, technology gap and shadow price of coal-fuelled power plants in China: A parametric meta-frontier analysis. Resource and Energy Economics, 43, 14-32.

Ebert, U., \& Welsch, H. (2007). Environmental emissions and production economics: implications of the materials balance. American Journal of Agricultural Economics, 89(2), 287-293.

Färe, R., Grosskopf, S., Lovell, C. K., \& Pasurka, C. (1989). Multilateral productivity comparisons when some outputs are undesirable: a nonparametric approach. The review of Economics and Statistics, 71(1), 90-98.

Färe, R., Grosskopf, S., \& Pasurka, C. (2013). Joint Production of Good and Bad Outputs with a Network Application, in Shogren, J. F., edited, Encyclopedia of energy, natural resource, and environmental economics, 109-118. London: Elsevier.

Førsund, F. R. (2009). Good modelling of bad outputs: pollution and multiple-output production. International Review of Environmental and Resource Economics, 3(1), 1-38.

Hailu, A., \& Veeman, T. S. (2001). Non-parametric productivity analysis with undesirable outputs: an application to the Canadian pulp and paper industry. American Journal of Agricultural Economics, 83(3), 605-616.

Halkos, G. E., Tzeremes, N. G., \& Kourtzidis, S. A. (2016). Measuring Sustainability Efficiency Using 
a Two-Stage Data Envelopment Analysis Approach. Journal of Industrial Ecology, 20(5), 11591175.

Hampf, B. (2014). Separating environmental efficiency into production and abatement efficiency: a nonparametric model with application to US power plants. Journal of Productivity Analysis, 41(3), 457-473.

Hampf, B., \& Rødseth, K. L. (2015). Carbon dioxide emission standards for US power plants: An efficiency analysis perspective. Energy Economics, 50, 140-153.

Hoang, V. N., \& Rao, D. P. (2010). Measuring and decomposing sustainable efficiency in agricultural production: A cumulative exergy balance approach. Ecological economics, 69(9), 1765-1776.

Kneese, A. V., Ayres, R. U., \& d'Arge, R. C. (1970). Economics and the Environment: A Materials Balance Approach. Baltimore, Maryland: Johns Hopkins University Press.

Krysiak, F. C., \& Krysiak, D. (2003). Production, consumption, and general equilibrium with physical constraints. Journal of Environmental Economics and Management, 46(3), 513-538.

Kuosmanen, N. (2014). Estimating stocks and flows of nitrogen: Application of dynamic nutrient balance to European agriculture. Ecological economics, 108, 68-78.

Kuosmanen, N., \& Kuosmanen, T. (2013). Modeling cumulative effects of nutrient surpluses in agriculture: a dynamic approach to material balance accounting. Ecological economics, 90, 159167.

Kuosmanen, T. (2005). Weak disposability in nonparametric production analysis with undesirable outputs. American Journal of Agricultural Economics, 87(4), 1077-1082.

Lam, P. L., \& Shiu, A. (2001). A data envelopment analysis of the efficiency of China's thermal power generation. Utilities Policy, 10(2), 75-83.

Lam, P. L., \& Shiu, A. (2004). Efficiency and productivity of China's thermal power generation. Review of Industrial Organization, 24(1), 73-93.

Lauwers, L. (2009). Justifying the incorporation of the materials balance principle into frontierbased eco-efficiency models. Ecological Economics, 68(6), 1605-1614.

Liu, W., Tian, J., Chen, L., Lu, W., \& Gao, Y. (2015). Environmental Performance Analysis of EcoIndustrial Parks in China: A Data Envelopment Analysis Approach. Journal of Industrial Ecology, 19(6), 1070-1081.

Ma, C., \& Zhao, X. (2015). China's electricity market restructuring and technology mandates: Plant-level evidence for changing operational efficiency. Energy Economics, 47, 227-237.

Masternak-Janus, A., \& Rybaczewska-Błażejowska, M. (2017). Comprehensive Regional EcoEfficiency Analysis Based on Data Envelopment Analysis: The Case of Polish Regions. Journal of Industrial Ecology, 21(1), 180-190.

Molinos-Senante, M., Hernández-Sancho, F., Mocholí-Arce, M., \& Sala-Garrido, R. (2014). Economic and environmental performance of wastewater treatment plants: potential reductions in greenhouse gases emissions. Resource and Energy Economics, 38, 125-140.

Murty, S., Russell, R. R., \& Levkoff, S. B. (2012). On modeling pollution-generating technologies. Journal of Environmental Economics and Management, 64(1), 117-135.Noll, R. G., \& Trijonis, J. (1971). Mass balance, general equilibrium, and environmental externalities. The American Economic Review, 61(4), 730-735. 
Pérez-Rincón, M. A. (2006). Colombian international trade from a physical perspective: Towards an ecological "Prebisch thesis". Ecological Economics, 59(4), 519-529.

Pethig, R. (2003). The'materials balance approach'to pollution: its origin, implications and acceptance (No. 105-03). Volkswirtschaftliche Diskussionsbeiträge, 1-31.

Pethig, R. (2006). Non-linear production, abatement, pollution and materials balance reconsidered. Journal of Environmental Economics and Management, 51(2), 185-204.

Picazo-Tadeo, A. J., Reig-Martinez, E., \& Hernandez-Sancho, F. (2005). Directional distance functions and environmental regulation. Resource and Energy Economics, 27(2), 131-142.

Rødseth, K. L. (2016). Environmental efficiency measurement and the materials balance condition reconsidered. European Journal of Operational Research, 250(1), 342-346.

Rødseth, K. L. (2017). Axioms of a polluting technology: a materials balance approach. Environmental and Resource Economics, 67(1), 1-22.

Sahoo, B. K., Luptacik, M., \& Mahlberg, B. (2011). Alternative measures of environmental technology structure in DEA: An application. European Journal of Operational Research, 215(3), 750-762.

Ščasný, M., Kovanda, J., \& Hák, T. (2003). Material flow accounts, balances and derived indicators for the Czech Republic during the 1990s: results and recommendations for methodological improvements. Ecological Economics, 45(1), 41-57.

Seiford, L. M., \& Zhu, J. (2002). Modeling undesirable factors in efficiency evaluation. European Journal of Operational Research, 142(1), 16-20.

Shi, X. (2010). Restructuring in China's State-owned Enterprises: Evidence from the Coal Industry. China \& World Economy, 18(3), 90-105.

Shi, X., \& Grafton, R. Q. (2010). Efficiency impacts of the Chinese industrial transition: a quantitative evaluation of reforms in the coal industry. Economic Change and Restructuring, 43(1), 1-19.

Song, C., Li, M., Zhang, F., He, Y. L., \& Tao, W. Q. (2015). A data envelopment analysis for energy efficiency of coal-fired power units in China. Energy Conversion and Management, 102, 121-130.

Sueyoshi, T., \& Goto, M. (2012). Data envelopment analysis for environmental assessment: comparison between public and private ownership in petroleum industry. European Journal of Operational Research, 216(3), 668-678.

Vatn, A. (1998). Input versus emission taxes: environmental taxes in a mass balance and transaction costs perspective. Land Economics, 74(4), 514-525.

Vázquez-Rowe, I., Iribarren, D., Hospido, A., Moreira, M. T., \& Feijoo, G. (2011). Computation of operational and environmental benchmarks within selected Galician fishing fleets. Journal of Industrial Ecology, 15(5), 776-795.

Wang, K., Lee, C. Y., Zhang, J., \& Wei, Y. M. (2016a). Operational performance management of the power industry: A distinguishing analysis between effectiveness and efficiency. Annals of Operations Research, doi: 10.1007/s10479-016-2189-1.

Wang, K., \& Wei, Y. M. (2014). China's regional industrial energy efficiency and carbon emissions abatement costs. Applied Energy, 130, 617-631.

Wang, K., Wei, Y. M., \& Huang, Z. (2017a). Environmental efficiency and abatement efficiency measurements of China's thermal power industry: A data envelopment analysis based materials 
balance approach. European Journal of Operational Research, doi: 10.1016/j.ejor.2017.04.053.

Wang, K, Xian, Y, Zhang, J, Li, Y, \& Che, L. (2016b). Potential carbon emission abatement cost recovery from carbon emission trading in China: An estimation of industry sector. Journal of Modelling in Management, 11(3), 842-854.

Wang, K., Zhang, J., \& Wei, Y. M. (2017b). Operational and environmental performance in China's thermal power industry: Taking an effectiveness measure as complement to an efficiency measure. Journal of Environmental Management, 192, 254-270.

Wei, C., Löschel, A., \& Liu, B. (2013). An empirical analysis of the $\mathrm{CO}_{2}$ shadow price in Chinese thermal power enterprises. Energy Economics, 40, 22-31.

Welch, E., \& Barnum, D. (2009). Joint environmental and cost efficiency analysis of electricity generation. Ecological Economics, 68(8), 2336-2343.

Yang, H., \& Pollitt, M. (2009). Incorporating both undesirable outputs and uncontrollable variables into DEA: The performance of Chinese coal-fired power plants. European Journal of Operational Research, 197(3), 1095-1105.

Yang, H., \& Pollitt, M. (2010). The necessity of distinguishing weak and strong disposability among undesirable outputs in DEA: environmental performance of Chinese coal-fired power plants. Energy Policy, 38(8), 4440-4444. 


\section{Tables}

Table 1 Ecological and cost efficiency results

\begin{tabular}{|c|c|c|c|c|}
\hline Efficiency measurement & Mean & St. Dev. & Minimum & Maximum \\
\hline Ecological efficiency $(E E)$ & 0.8635 & 0.1366 & 0.5043 & 1.0000 \\
\hline Ecological technical efficiency (ETE) & 0.9111 & 0.1205 & 0.5633 & 1.0000 \\
\hline Ecological allocative efficiency $(E A E)$ & 0.9498 & 0.0931 & 0.5043 & 1.0000 \\
\hline Cost efficiency $(C E)$ & 0.8452 & 0.1403 & 0.5073 & 1.0000 \\
\hline Cost technical efficiency (CTE) & 0.9027 & 0.1291 & 0.5090 & 1.0000 \\
\hline Cost allocative efficiency $(C A E)$ & 0.9400 & 0.1018 & 0.5555 & 1.0000 \\
\hline Total cost efficiency (TCE) & 0.8453 & 0.1403 & 0.5075 & 1.0000 \\
\hline Total cost technical efficiency (TCTE) & 0.9108 & 0.1207 & 0.5630 & 1.0000 \\
\hline Total cost allocative efficiency (TCAE) & 0.9300 & 0.1001 & 0.5555 & 1.0000 \\
\hline
\end{tabular}

Note: St. Dev. = standard deviation.

Table 2 Changes on energy input and $\mathrm{SO}_{2}$ emissions associated with efficiency changes

\begin{tabular}{|c|c|c|c|}
\hline Energy and $\mathrm{SO}_{2}$ & Unit & Value change & Percentage change \\
\hline Coal, observation to $T E$ & Million tonne & -103.47 & $-6.6 \%$ \\
\hline Oil, observation to $T E$ & Thousand tonne & -908.99 & $-36.2 \%$ \\
\hline Natural gas, observation to $T E$ & Million $\mathrm{m}^{3}$ & -1754.02 & $-8.5 \%$ \\
\hline $\mathrm{SO}_{2}$, observation to $T E$ & Tonne & -421132.61 & $-7.8 \%$ \\
\hline Coal, observation to $E E$ & Million tonne & -239.26 & $-15.3 \%$ \\
\hline Oil, observation to $E E$ & Thousand tonne & -78.98 & $-3.1 \%$ \\
\hline Natural gas, observation to $E E$ & Million $\mathrm{m}^{3}$ & 18102.26 & $87.9 \%$ \\
\hline $\mathrm{SO}_{2}$, observation to $E E$ & Tonne & -818339.14 & $-15.2 \%$ \\
\hline $\mathrm{SO}_{2}, \mathrm{TE}$ to $E E$ & Tonne & -397206.53 & $-8.0 \%$ \\
\hline Coal, observation to $T C E$ & Million tonne & -179.68 & $-11.5 \%$ \\
\hline Oil, observation to $T C E$ & Thousand tonne & -1008.95 & $-40.1 \%$ \\
\hline Natural gas, observation to $T C E$ & Million $\mathrm{m}^{3}$ & -8603.77 & $-41.8 \%$ \\
\hline $\mathrm{SO}_{2}$, observation to $T C E$ & Tonne & -709859.13 & $-13.2 \%$ \\
\hline $\mathrm{SO}_{2}, T E$ to $T C E$ & Tonne & -288726.52 & $-5.8 \%$ \\
\hline
\end{tabular}

Note: $\mathrm{SO}_{2}=$ sulfur dioxide; $\mathrm{m}^{3}=$ cubic meters. 
Table 3 Ecological and economic trade-offs with respect to changes in cost

\begin{tabular}{|c|c|c|c|c|c|c|c|c|c|}
\hline \multirow[b]{2}{*}{$\begin{array}{l}\text { Regional } \\
\text { sector code }\end{array}$} & \multirow[b]{2}{*}{ Region } & \multirow{2}{*}{$\begin{array}{l}\text { Generation cost } \\
\text { per unit } \\
\text { electricity } \\
\text { (Yuan/kWh) }\end{array}$} & \multicolumn{7}{|c|}{ Percentage changes in generation cost per unit electricity (\%) } \\
\hline & & & $\begin{array}{l}\text { Observation } \\
\text { to } T E\end{array}$ & $\begin{array}{l}\text { Observation } \\
\text { to } E E\end{array}$ & $\begin{array}{l}\text { Observation } \\
\text { to } T C E\end{array}$ & $T E$ to $E E$ & $T E$ to $T C E$ & $T C E$ to $E E$ & $E E$ to $T C E$ \\
\hline 1 & Beijing & 0.320 & 0.0 & 0.0 & -19.8 & 0.0 & -19.9 & 25.7 & -19.9 \\
\hline 2 & Tianjin & 0.329 & -12.5 & -3.5 & -12.7 & 9.9 & -0.2 & 10.1 & -9.5 \\
\hline 3 & Hebei & 0.342 & -0.5 & 3.4 & -2.0 & 3.9 & -1.6 & 5.5 & -5.3 \\
\hline 4 & Inner Mongolia & 0.249 & 0.0 & -36.1 & -36.9 & -36.0 & -36.8 & 2.5 & -2.4 \\
\hline 5 & Jilin & 0.324 & -41.1 & -42.9 & -43.1 & -3.5 & -3.9 & 0.5 & -0.5 \\
\hline 6 & Heilongjiang & 0.325 & -33.8 & -34.3 & -34.4 & -0.8 & -0.8 & 0.1 & -0.1 \\
\hline 7 & Shanghai & 0.376 & 0.0 & 0.0 & -0.1 & 0.0 & -0.1 & 0.1 & -0.1 \\
\hline 8 & Jiangsu & 0.356 & -3.1 & -3.3 & -3.3 & -0.2 & -0.3 & 0.1 & -0.1 \\
\hline 9 & Zhejiang & 0.378 & -3.8 & -2.0 & -6.8 & 1.8 & -3.2 & 5.1 & -4.9 \\
\hline 10 & Anhui & 0.346 & 0.0 & 3.9 & 0.0 & 3.9 & 0.0 & 3.9 & -3.8 \\
\hline 11 & Fujian & 0.355 & -6.2 & -2.6 & -11.1 & 3.8 & -5.2 & 9.5 & -8.7 \\
\hline 12 & Jiangxi & 0.381 & -5.2 & -5.4 & -11.1 & -0.1 & -6.1 & 6.2 & -5.9 \\
\hline 13 & Shandong & 0.358 & -7.6 & -7.9 & -9.9 & -0.3 & -2.4 & 2.2 & -2.1 \\
\hline 14 & Henan & 0.346 & -14.6 & -8.6 & -16.1 & 7.0 & -1.8 & 9.0 & -8.2 \\
\hline 15 & Hubei & 0.375 & -13.4 & -12.8 & -14.2 & 0.6 & -0.9 & 1.5 & -1.5 \\
\hline 16 & Guangdong & 0.412 & -5.4 & 11.6 & -14.6 & 17.6 & -9.6 & 29.1 & -24.3 \\
\hline 17 & Guangxi & 0.374 & 0.0 & -1.4 & -1.4 & -1.4 & -1.4 & 0.1 & -0.1 \\
\hline 18 & Hainan & 0.391 & 0.0 & -9.0 & -25.2 & -9.0 & -25.2 & 20.7 & -17.6 \\
\hline 19 & Chongqing & 0.355 & 0.0 & -4.0 & -4.0 & -4.0 & -4.0 & 0.0 & 0.0 \\
\hline 20 & Sichuan & 0.366 & -13.2 & -15.7 & -15.7 & -2.7 & -2.7 & 0.0 & 0.0 \\
\hline 21 & Guizhou & 0.306 & -15.5 & -16.8 & -16.8 & -1.6 & -1.6 & 0.0 & 0.0 \\
\hline 22 & Shaanxi & 0.316 & -4.0 & -9.3 & -9.3 & -5.5 & -5.5 & 0.0 & 0.0 \\
\hline 23 & Qinghai & 0.284 & -33.7 & -32.6 & -33.8 & 2.5 & -0.3 & 2.8 & -2.7 \\
\hline 24 & Ningxia & 0.230 & -4.6 & -6.8 & -6.9 & -2.4 & -2.5 & 0.0 & 0.0 \\
\hline 25 & Xinjiang & 0.205 & -21.7 & -23.9 & -25.2 & -3.9 & -6.3 & 2.7 & -2.6 \\
\hline- & Mean & 0.336 & -9.1 & -9.3 & -14.3 & -0.3 & -5.8 & 5.9 & -5.6 \\
\hline
\end{tabular}

Note: $\mathrm{kWh}=$ kilowatt-hours. 
Table 4 Ecological and economic trade-offs with respect to changes in pollution

\begin{tabular}{|c|c|c|c|c|c|c|c|c|c|}
\hline \multirow{2}{*}{$\begin{array}{l}\text { Regional } \\
\text { sector code }\end{array}$} & \multirow[b]{2}{*}{ Region } & \multirow{2}{*}{$\begin{array}{l}\mathrm{SO}_{2} \text { emissions } \\
\text { per unit } \\
\text { electricity } \\
\text { (g/kWh) }\end{array}$} & \multicolumn{7}{|c|}{ Percentage changes in $\mathrm{SO}_{2}$ emissions per unit electricity $(\%)$} \\
\hline & & & $\begin{array}{l}\text { Observation } \\
\text { to } T E\end{array}$ & $\begin{array}{l}\text { Observation } \\
\text { to } E E\end{array}$ & $\begin{array}{l}\text { Observation } \\
\text { to } T C E\end{array}$ & $T E$ to $E E$ & $T E$ to $T C E$ & $T C E$ to $E E$ & $E E$ to $T C E$ \\
\hline 1 & Beijing & 0.346 & 0.0 & 0.0 & 71.9 & 0.0 & 71.9 & -41.8 & 71.9 \\
\hline 2 & Tianjin & 1.008 & -8.1 & -12.1 & -8.2 & -4.4 & -0.1 & -4.3 & 4.5 \\
\hline 3 & Hebei & 1.270 & -0.5 & -6.8 & -2.9 & -6.3 & -2.4 & -4.0 & 4.1 \\
\hline 4 & Inner Mongolia & 2.027 & 0.0 & -42.9 & -40.5 & -42.9 & -40.5 & -4.0 & 4.2 \\
\hline 5 & Jilin & 2.084 & -39.9 & -41.8 & -41.8 & -3.2 & -3.1 & -0.1 & 0.1 \\
\hline 6 & Heilongjiang & 2.226 & -30.8 & -30.8 & -30.7 & -0.1 & 0.1 & -0.1 & 0.1 \\
\hline 7 & Shanghai & 0.628 & 0.0 & 0.0 & 1.8 & 0.0 & 1.8 & -1.8 & 1.8 \\
\hline 8 & Jiangsu & 0.988 & -2.7 & -3.1 & -3.0 & -0.4 & -0.3 & 0.0 & 0.0 \\
\hline 9 & Zhejiang & 0.985 & -3.2 & -3.7 & 0.2 & -0.5 & 3.6 & -3.9 & 4.1 \\
\hline 10 & Anhui & 0.604 & 0.0 & -7.3 & 0.0 & -7.3 & 0.0 & -7.3 & 7.9 \\
\hline 11 & Fujian & 0.597 & -6.1 & -8.6 & -0.4 & -2.6 & 6.0 & -8.2 & 8.9 \\
\hline 12 & Jiangxi & 1.664 & -3.9 & -10.8 & -10.0 & -7.3 & -6.4 & -1.0 & 1.0 \\
\hline 13 & Shandong & 1.971 & -6.6 & -9.9 & -8.7 & -3.5 & -2.3 & -1.3 & 1.3 \\
\hline 14 & Henan & 1.440 & -15.9 & -18.4 & -15.9 & -3.0 & -0.1 & -3.0 & 3.1 \\
\hline 15 & Hubei & 2.153 & -11.3 & -11.6 & -11.1 & -0.3 & 0.2 & -0.5 & 0.5 \\
\hline 16 & Guangdong & 0.825 & -4.5 & -8.8 & 2.2 & -4.6 & 6.9 & -10.8 & 12.1 \\
\hline 17 & Guangxi & 1.666 & 0.0 & -2.8 & -2.8 & -2.8 & -2.8 & 0.0 & 0.0 \\
\hline 18 & Hainan & 0.747 & 0.0 & -8.4 & 0.8 & -8.4 & 0.8 & -9.1 & 10.1 \\
\hline 19 & Chongqing & 5.339 & 0.0 & -3.1 & -3.1 & -3.1 & -3.1 & 0.0 & 0.0 \\
\hline 20 & Sichuan & 3.979 & -12.0 & -15.0 & -15.0 & -3.4 & -3.4 & -0.1 & 0.1 \\
\hline 21 & Guizhou & 4.632 & -12.9 & -14.1 & -14.1 & -1.4 & -1.4 & 0.0 & 0.0 \\
\hline 22 & Shaanxi & 2.473 & -3.6 & -9.6 & -9.6 & -6.3 & -6.3 & 0.0 & 0.0 \\
\hline 23 & Qinghai & 2.126 & -25.9 & -26.5 & -25.9 & -0.8 & 0.1 & -0.9 & 0.9 \\
\hline 24 & Ningxia & 1.593 & -4.5 & -7.6 & -7.5 & -3.3 & -3.2 & -0.1 & 0.1 \\
\hline 25 & Xinjiang & 1.838 & -18.5 & -22.2 & -21.5 & -4.5 & -3.7 & -0.9 & 0.9 \\
\hline- & Mean & 1.808 & -10.0 & -14.6 & -12.9 & -5.1 & -3.2 & -2.0 & 2.1 \\
\hline
\end{tabular}

Note: $\mathrm{SO}_{2}=$ sulfur dioxide; $\mathrm{g} / \mathrm{kWh}=$ grams per kilowatt-hour. 
Table 5 Shadow cost and shadow pollution estimation results

\begin{tabular}{|c|c|c|c|c|c|c|c|c|}
\hline $\begin{array}{l}\text { Regional } \\
\text { sector } \\
\text { code }\end{array}$ & Region & $\begin{array}{l}S C \\
\text { (Million } \\
\text { Yuan) }\end{array}$ & $\begin{array}{l}S C \text { per unit } \\
\text { electricity } \\
\text { (Yuan/kWh) }\end{array}$ & $\begin{array}{l}S C \text { per unit electricity / } \\
\text { cost per unit electricity } \\
(\%)\end{array}$ & $\begin{array}{l}\text { SP } \\
\text { (Thousand } \\
\text { tonne) }\end{array}$ & $\begin{array}{l}S P \text { per unit } \\
\text { electricity } \\
(\mathrm{g} / \mathrm{kWh})\end{array}$ & $\begin{array}{l}S P \text { per unit electricity } \\
/ \mathrm{SO}_{2} \text { per unit } \\
\text { electricity }(\%)\end{array}$ & $\begin{array}{l}S C \text { per unit } \\
S_{2} \text { (Yuan/g) }\end{array}$ \\
\hline 1 & Beijing & 2656.89 & 0.089 & 27.8 & 7.43 & 0.249 & 71.9 & 0.357 \\
\hline 2 & Tianjin & 1547.31 & 0.025 & 7.7 & 2.41 & 0.039 & 3.9 & 0.643 \\
\hline 3 & Hebei & 4578.60 & 0.020 & 6.0 & 11.01 & 0.049 & 3.9 & 0.416 \\
\hline 4 & Inner Mongolia & 1286.18 & 0.004 & 1.8 & 14.12 & 0.048 & 2.4 & 0.091 \\
\hline 5 & Jilin & 69.14 & 0.001 & 0.4 & 0.06 & 0.001 & 0.1 & 1.077 \\
\hline 6 & Heilongjiang & 11.82 & 0.000 & 0.0 & 0.15 & 0.002 & 0.1 & 0.078 \\
\hline 7 & Shanghai & 34.44 & 0.000 & 0.1 & 1.01 & 0.011 & 1.8 & 0.034 \\
\hline 8 & Jiangsu & 65.92 & 0.000 & 0.0 & 0.17 & 0.000 & 0.0 & 0.390 \\
\hline 9 & Zhejiang & 3977.82 & 0.017 & 4.5 & 8.99 & 0.039 & 3.9 & 0.443 \\
\hline 10 & Anhui & 2338.50 & 0.012 & 3.5 & 8.52 & 0.044 & 7.3 & 0.274 \\
\hline 11 & Fujian & 4095.96 & 0.033 & 9.4 & 5.95 & 0.049 & 8.1 & 0.689 \\
\hline 12 & Jiangxi & 1354.76 & 0.020 & 5.2 & 1.00 & 0.015 & 0.9 & 1.352 \\
\hline 13 & Shandong & 2613.26 & 0.008 & 2.2 & 7.44 & 0.023 & 1.1 & 0.351 \\
\hline 14 & Henan & 8089.61 & 0.032 & 9.1 & 9.23 & 0.036 & 2.5 & 0.877 \\
\hline 15 & Hubei & 287.43 & 0.003 & 0.9 & 0.87 & 0.010 & 0.5 & 0.329 \\
\hline 16 & Guangdong & 26801.60 & 0.090 & 21.9 & 27.00 & 0.091 & 11.0 & 0.993 \\
\hline 17 & Guangxi & 10.32 & 0.000 & 0.0 & 0.03 & 0.000 & 0.0 & 0.358 \\
\hline 18 & Hainan & 1193.89 & 0.064 & 16.3 & 1.29 & 0.069 & 9.2 & 0.923 \\
\hline 19 & Chongqing & 0.00 & 0.000 & 0.0 & 0.00 & 0.000 & 0.0 & - \\
\hline 20 & Sichuan & 3.78 & 0.000 & 0.0 & 0.10 & 0.002 & 0.0 & 0.036 \\
\hline 21 & Guizhou & 1.43 & 0.000 & 0.0 & 0.04 & 0.000 & 0.0 & 0.032 \\
\hline 22 & Shaanxi & 0.00 & 0.000 & 0.0 & 0.00 & 0.000 & 0.0 & - \\
\hline 23 & Qinghai & 94.24 & 0.008 & 2.8 & 0.16 & 0.014 & 0.6 & 0.588 \\
\hline 24 & Ningxia & 9.25 & 0.000 & 0.0 & 0.09 & 0.001 & 0.1 & 0.107 \\
\hline 25 & Xinjiang & 798.29 & 0.007 & 3.5 & 1.41 & 0.013 & 0.7 & 0.568 \\
\hline- & Mean & 2476.82 & 0.017 & 5.2 & 4.34 & 0.032 & 1.8 & 0.571 \\
\hline
\end{tabular}

Note: $\mathrm{SO}_{2}=$ sulfur dioxide; $\mathrm{g} / \mathrm{kWh}=$ grams per kilowatt-hour. 
Table 6 Impacts of $\mathrm{SO}_{2}$ pollution taxes on cost and emission levels

\begin{tabular}{|c|c|c|c|}
\hline Scenario & Variable & Unit & Mean value \\
\hline \multirow{5}{*}{ Current $\mathrm{SO}_{2}$ discharge fee } & Observed unit cost & Yuan/kWh & 0.420 \\
\hline & Observed unit $\mathrm{SO}_{2}$ emissions & $\mathrm{g} / \mathrm{kWh}$ & 1.808 \\
\hline & Unit cost at cost efficient point & Yuan/kWh & 0.330 \\
\hline & Unit $\mathrm{SO}_{2}$ emissions at cost efficient point & $\mathrm{g} / \mathrm{kWh}$ & 1.568 \\
\hline & Shadow cost per unit $\mathrm{SO}_{2}$ & Yuan/g & 0.571 \\
\hline \multirow{4}{*}{$\begin{array}{l}\text { Planned } \mathrm{SO}_{2} \text { pollution tax (lower } \\
\text { bound) }\end{array}$} & Estimated unit cost at cost efficient point & Yuan/kWh & 0.331 \\
\hline & Changes on unit cost at cost efficient point & $\%$ & 0.491 \\
\hline & Changes on unit $\mathrm{SO}_{2}$ emissions at cost efficient point & $\%$ & -0.0003 \\
\hline & Shadow cost per unit $\mathrm{SO}_{2}$ & Yuan/g & 0.569 \\
\hline \multirow{4}{*}{$\begin{array}{l}\text { Planned } \mathrm{SO}_{2} \text { pollution tax (upper } \\
\text { bound) }\end{array}$} & Estimated unit cost at cost efficient point & Yuan/kWh & 0.349 \\
\hline & Changes on unit cost at cost efficient point & $\%$ & 5.703 \\
\hline & Changes on unit $\mathrm{SO}_{2}$ emissions at cost efficient point & $\%$ & -0.016 \\
\hline & Shadow cost per unit $\mathrm{SO}_{2}$ & Yuan/g & 0.564 \\
\hline
\end{tabular}

Note: $\mathrm{SO}_{2}=$ sulfur dioxide; $\mathrm{g} / \mathrm{kWh}$ = grams per kilowatt-hour. 


\section{Supplementary material}

\section{Weak G-disposability based summing-up formulation of MBP}

The MBP states that the total amount of mass in the polluting inputs should equal the mass in desirable outputs plus the mass in the residuals that cause pollution. Based on the concept of weak G-disposability, a summingup formulation of the MBP can be derived. This approach implies that the increase in pollutions $(\Delta \boldsymbol{b})$ should equal the sum of the increase in polluting mass in inputs $(\boldsymbol{\alpha} \Delta \boldsymbol{e})$, the decrease in polluting mass bound in desirable outputs $(\boldsymbol{\beta} \Delta \boldsymbol{y})$, and the decrease in abatements of pollutions $(\Delta \boldsymbol{a})$. The summing-up formulation of weak G-disposability is defined as $\Delta \boldsymbol{b}=\boldsymbol{\alpha} \Delta \boldsymbol{e}+\boldsymbol{\beta} \Delta \boldsymbol{y}+\Delta \boldsymbol{a}$, which is equivalent to Equation (1) in the paper, because the increase in pollution is due to the increase in polluting input consumption and/or the reduction in desirable output production, as well as the decrease in pollution abatements.

\section{DEA based models for ecological and economic efficiency measurement}

In this study, we propose three DEA based MBP methods for efficiency measurement. Suppose there is a sample of $n$ firms having desirable outputs, non-polluting (i.e., non-energy) inputs, polluting (energy) inputs, and produced (not discharged) undesirable outputs (i.e., pollutions) denoted by $\left(y_{r j}, x_{i j}, e_{i j}, b_{i j}\right)$, where $i=1, \ldots, m_{1}$ (for $x$ ), $i=m_{1}+1, \ldots, m$ (for $e$ and $b$ ), $r=1, \ldots, s$, and $j=1, \ldots, n$.

We first propose the following minimization programming (S1) for efficiency measurement with MBP for the currently under estimating firm $j_{0}$ :

$\min \theta^{T}$

$$
\begin{array}{ll}
\text { s.t. } & y_{r j_{0}}=\sum_{j=1}^{n} \lambda_{j} y_{r j}-d_{r j}^{T y}, r=1, \ldots, s \\
& x_{i j_{0}}=\sum_{j=1}^{n} \lambda_{j} x_{i j}+d_{i j}^{T x}, i=1, \ldots, m_{1} \\
& \theta^{T} e_{i j_{0}}=\sum_{j=1}^{n} \lambda_{j} e_{i j}+d_{i j}^{T e}, i=m_{1}+1, \ldots, m \\
\theta^{T} b_{i j_{0}} & =\sum_{j=1}^{n} \lambda_{j} b_{i j}+d_{i j}^{T b}, i=m_{1}+1, \ldots, m \\
& \alpha_{i j} d_{i j}^{T e}=d_{i j}^{T b}, i=m_{1}+1, \ldots, m, j=1, \ldots, n
\end{array}
$$

In programming (S1), $\theta^{T}$ is a variable for proportionally adjusting all energy inputs and the associated pollution outputs; $\lambda_{j}$ are intensity variables representing convex combination; $d_{r j}^{T y}, d_{i j}^{T x}, d_{i j}^{T e}$ and $d_{i j}^{T b}$ are slack variables implementing the weak G-disposability for the MBP; $\alpha_{i j}$ are emission factors indicating unit polluting mass bound in energy inputs. The last constraint associated with the third and fourth ones in programming (S1) guarantee the MBP. The objective of programming (S1) is to proportionally shirking all observed energy inputs $e_{i}$ for the currently under estimating firm $j_{0}$ until they are projected onto the frontier of the technology set.

Then, we consider that given the amounts of desirable outputs $y_{r}$ to be produced, what combination of energy inputs $e_{i}$ would result in the lowest possible amounts of pollutions $b_{i}$ ? The following minimization programming (S2) approaches this question through achieving the minimal amounts of polluting mass bound in all energy inputs, i.e., $\sum_{i=m_{1}+1}^{m} \alpha_{i j_{0}} \theta_{i}^{E} e_{i j_{0}}$, given desirable outputs $y_{r}$ and non-energy inputs $x_{i}$ unchanged, for the currently under estimating firm $j_{0}$ :

$$
\begin{array}{ll}
\min & \sum_{i=m_{1}+1}^{m} \alpha_{i j_{0}} \theta_{i}^{E} e_{i j_{0}} \\
\text { s.t. } & y_{r j_{0}}=\sum_{j=1}^{n} \lambda_{j} y_{r j}-d_{r j}^{E y}, r=1, \ldots, s \\
& x_{i j_{0}}=\sum_{j=1}^{n} \lambda_{j} x_{i j}+d_{i j}^{E x}, i=1, \ldots, m_{1} \\
& \theta_{i}^{E} e_{i j_{0}}=\sum_{j=1}^{n} \lambda_{j} e_{i j}+d_{i j}^{E e}, i=m_{1}+1, \ldots, m \\
& \theta_{i}^{E} b_{i j_{0}}=\sum_{j=1}^{n} \lambda_{j} b_{i j}+d_{i j}^{E b}, i=m_{1}+1, \ldots, m
\end{array}
$$




$$
\alpha_{i j} d_{i j}^{E e}=d_{i j}^{E b}, i=m_{1}+1, \ldots, m, j=1, \ldots, n
$$

In programming (S2), $\theta_{i}^{E}$ is variables for proportionally adjusting each type of energy input $e_{i}$ and its associated pollution outputs $b_{i}$, but the adjustments can be non-proportional for different types of energy inputs so as the resources allocative efficiency, i.e., the measure of trade-offs among different types of energy used by a firm, can be included in efficiency measurement. Similarly, $\lambda_{j}$ are intensity variables; $\alpha_{i j}$ are emission factors, $d_{r j}^{E y}, d_{i j}^{E x}, d_{i j}^{E e}$ and $d_{i j}^{E b}$ are slack variables implementing the weak G-disposability for the MBP. The last constraint in programming (S2) guarantees the MBP.

Thirdly, if the price information on the energy inputs $\left(p_{i j}\right)$ is accessible, we could obtain the minimal amount of cost on energy inputs through the following minimization programming (S3):

$$
\begin{array}{ll}
\min & \sum_{i=m_{1}+1}^{m} p_{i j_{0}} \theta_{i}^{C} e_{i j_{0}} \\
\text { s.t. } & y_{r j_{0}}=\sum_{j=1}^{n} \lambda_{j} y_{r j}-d_{r j}^{C y}, r=1, \ldots, s \\
& x_{i j_{0}}=\sum_{j=1}^{n} \lambda_{j} x_{i j}+d_{i j}^{C x}, i=1, \ldots, m_{1} \\
& \theta_{i}^{C} e_{i j_{0}}=\sum_{j=1}^{n} \lambda_{j} e_{i j}+d_{i j}^{C e}, i=m_{1}+1, \ldots, m \\
& \theta_{i}^{C} b_{i j_{0}}=\sum_{j=1}^{n} \lambda_{j} b_{i j}+d_{i j}^{C b}, i=m_{1}+1, \ldots, m \\
& \alpha_{i j} d_{i j}^{C e}=d_{i j}^{C b}, i=m_{1}+1, \ldots, m, j=1, \ldots, n
\end{array}
$$

In programming (S3), similar to programming (S2), $\theta_{i}^{C}$ are variables for non-proportionally adjusting different types of energy inputs $e_{i}$ for achieving the minimal cost of energy inputs, i.e., $\sum_{i=m_{1}+1}^{m} p_{i j_{0}} \theta_{i}^{C} e_{i j_{0}}$, given desirable outputs $y_{r}$ and non-energy inputs $x_{i}$ fixed, for the currently under estimating firm $j_{0}$. This procedure makes the measurement of cost allocative efficiency possible. In programming (S3) $\lambda_{j}$ are intensity variables; $\alpha_{i j}$ are emission factors; $d_{r j}^{C y}, d_{i j}^{C x}, d_{i j}^{C e}$ and $d_{i j}^{C b}$ are slack variables implementing the weak G-disposability; and the last constraint guarantees the MBP. 


\section{Supplementary tables}

Supplementary table 1 Summary statics of inputs and outputs

\begin{tabular}{|c|c|c|c|c|c|c|c|c|c|c|}
\hline \multirow{2}{*}{ Year } & Variable & Coal & Oil & Natural gas & Capacity & Staff & Electricity & $\begin{array}{l}\mathrm{SO}_{2} \text { from } \\
\text { coal }\end{array}$ & $\begin{array}{l}\mathrm{SO}_{2} \text { from } \\
\text { oil }\end{array}$ & $\begin{array}{l}\mathrm{SO}_{2} \text { from } \\
\text { natural gas }\end{array}$ \\
\hline & Unit & $\begin{array}{l}\text { Million } \\
\text { tonne }\end{array}$ & $\begin{array}{l}\text { Thousand } \\
\text { tonne }\end{array}$ & Million $\mathrm{m}^{3}$ & Million kW & $\begin{array}{l}\text { Thousand } \\
\text { person }\end{array}$ & Billion kWh & Tonne & Tonne & Tonne \\
\hline \multirow[t]{4}{*}{2011} & Mean & 63.34 & 120.67 & 835.43 & 26.28 & 26.33 & 131.55 & $213,960.76$ & $1,289.20$ & 463.84 \\
\hline & St. Dev. & 51.73 & 162.69 & $1,169.35$ & 20.10 & 16.23 & 104.45 & $171,714.12$ & $1,492.34$ & 587.68 \\
\hline & Maximum & 191.86 & 508.60 & $3,819.00$ & 64.92 & 61.60 & 355.19 & $599,191.03$ & $5,166.60$ & $1,953.63$ \\
\hline & Minimum & 5.57 & 0.30 & 2.00 & 2.30 & 4.00 & 9.18 & $9,010.88$ & 2.75 & 5.15 \\
\hline \multirow[t]{4}{*}{2012} & Mean & 63.33 & 117.45 & 895.91 & 28.19 & 25.14 & 131.59 & $223,243.73$ & $1,329.49$ & 519.69 \\
\hline & St. Dev. & 54.86 & 161.15 & $1,242.08$ & 21.70 & 16.44 & 106.76 & $183,056.70$ & $1,617.17$ & 700.91 \\
\hline & Maximum & 202.62 & 533.70 & $4,395.00$ & 70.80 & 54.91 & 366.97 & $687,063.36$ & $5,349.95$ & $2,665.36$ \\
\hline & Minimum & 6.03 & 0.30 & 5.00 & 2.30 & 3.05 & 11.47 & 8,879.68 & 2.88 & 9.75 \\
\hline \multirow[t]{4}{*}{2013} & Mean & 63.51 & 95.74 & 873.96 & 29.42 & 24.36 & 146.05 & $244,907.83$ & $1,225.77$ & 569.11 \\
\hline & St. Dev. & 50.57 & 137.90 & $1,282.19$ & 22.24 & 15.09 & 113.54 & $189,185.59$ & $1,550.05$ & 780.79 \\
\hline & Maximum & 184.40 & 412.20 & $4,224.00$ & 75.53 & 52.80 & 406.87 & $753,017.46$ & $5,231.83$ & $2,808.64$ \\
\hline & Minimum & 6.33 & 0.30 & 9.00 & 2.35 & 2.94 & 13.44 & $11,483.69$ & 2.43 & 4.12 \\
\hline \multirow[t]{4}{*}{2014} & Mean & 62.64 & 95.90 & 923.23 & 31.62 & 23.10 & 146.81 & $170,590.64$ & 835.79 & 402.25 \\
\hline & St. Dev. & 51.00 & 140.91 & $1,394.07$ & 22.87 & 13.51 & 114.14 & $147,199.54$ & $1,017.63$ & 564.62 \\
\hline & Maximum & 193.67 & 453.20 & $4,088.00$ & 77.27 & 48.07 & 406.25 & $524,452.04$ & $3,269.25$ & $1,734.53$ \\
\hline & Minimum & 5.04 & 0.60 & 5.00 & 2.42 & 3.16 & 12.99 & $6,369.73$ & 3.80 & 4.45 \\
\hline
\end{tabular}


Supplementary table $2 \mathrm{SO}_{2}$ emission factors

\begin{tabular}{llll}
\hline & $\begin{array}{l}\text { Emission factor of coal } \\
(\mathrm{g} / \mathrm{kg})\end{array}$ & $\begin{array}{l}\text { Emission factor of oil } \\
(\mathrm{g} / \mathrm{kg})\end{array}$ & $\begin{array}{l}\text { Emission factor of natural gas } \\
\left(\mathrm{g} / \mathrm{m}^{3}\right)\end{array}$ \\
\hline Beijing & 1.44 & 6.31 & 0.35 \\
Tianjin & 2.18 & 9.56 & 0.53 \\
Hebei & 2.95 & 12.93 & 0.71 \\
Inner Mongolia & 3.06 & 13.38 & 0.73 \\
Jilin & 3.30 & 14.46 & 0.79 \\
Heilongjiang & 4.16 & 18.23 & 1.00 \\
Shanghai & 1.60 & 6.98 & 0.38 \\
Jiangsu & 2.38 & 10.40 & 0.57 \\
Zhejiang & 2.57 & 11.25 & 0.62 \\
Anhui & 1.46 & 6.39 & 0.34 \\
Fujian & 1.43 & 6.27 & 0.34 \\
Jiangxi & 3.89 & 17.05 & 0.94 \\
Shandong & 4.35 & 19.02 & 1.05 \\
Henan & 3.09 & 13.51 & 0.74 \\
Hubei & 4.99 & 21.85 & 1.20 \\
Guangdong & 2.09 & 9.14 & 0.50 \\
Guangxi & 4.11 & 17.98 & 1.02 \\
Hainan & 1.90 & 8.30 & 0.46 \\
Chongqing & 11.97 & 52.39 & 2.88 \\
Sichuan & 8.55 & 37.43 & 2.06 \\
Guizhou & 9.92 & 43.41 & 2.19 \\
Shaanxi & 5.28 & 23.12 & 1.27 \\
Qinghai & 3.92 & 17.14 & 0.94 \\
Ningxia & 2.81 & 12.30 & 0.72 \\
Xinjiang & 3.57 & 15.61 & 0.86 \\
\hline
\end{tabular}

Supplementary table $3 \mathrm{SO}_{2}$ pollution discharge fee rate or pollution tax rate (Yuan/kg)

\begin{tabular}{lll}
\hline $\begin{array}{l}\text { Current } \mathrm{SO}_{2} \text { discharge } \\
\text { fee rate, implemented } \\
\text { until } 2015\end{array}$ & $\begin{array}{l}\text { Planned } \mathrm{SO}_{2} \text { pollution tax rate (lower bound), } \\
\text { will start from 2018 }\end{array}$ & $\begin{array}{l}\text { Planned } \mathrm{SO}_{2} \text { pollution tax rate } \\
\text { (upper bound), will start from } \\
2018\end{array}$ \\
\hline $\begin{array}{l}1.26 \text { (Beijing), } 0.63 \text { (All } \\
\text { other regions) }\end{array}$ & $\begin{array}{l}10.00 \text { (Beijing), 6.30 (Tianjin), 2.40 (Hebei), } \\
\begin{array}{l}4.00 \text { (Shanghai), 3.00 (Shandong), 1.26 (All } \\
\text { other regions) }\end{array}\end{array}$ & 12.63 (All regions) \\
\hline
\end{tabular}




\section{Endnotes}

1 Oil consumption in China's thermal power plant are usually used for ignition and combustion-support. Note that the evaluation unit in this study is provincial thermal power industry sector which includes both coalfired and natural gas-fired power generators, and the related evaluation is not inner energy-type (different types of coal or different types of natural gas) substitution but the substitution between coal and natural gas.

2 All the estimations on efficiency scores and decrease (or increase) potentials of energy inputs and pollutant emissions are based on the observed data and current (2011-2014) technological frontier (technology) of thermal power electricity generation; in other words, our estimation is known as an ex post and static analysis. Thus, all derived policy implications are from the perspective of short-term economic and ecological analysis relying on current technology.

3 Because of the data limitation, we use the aggregated data but not the capacity-specific data on inputs and outputs for estimation. Then, the technical efficiency measures may have mixed effects of operating efficiency that could be possibly improved (e.g., the efficiency difference between two $300-\mathrm{mW}$ generators) and innate efficiency difference that is hard to improve (e.g., the efficiency difference between one $300-\mathrm{mW}$ generator and one $1,000-\mathrm{mW}$ generator). Therefore, one should be very careful when using these efficiency scores $(E E, C E$, $T C E$ and their decompositions) which can only be interpreted for average sector and from the macro-economic analysis perspective. Thanks to the reviewer for this issue.

${ }^{4}$ Note that the technologies for coal-fired and natural gas-fired power generation are different and they are not technically perfect substitutable, and this imperfect substitution also exists within different coal-fired power generation technologies. The estimation in this study mainly focuses on the macro-economic and environmental trade-off analysis at the regional level for the entire thermal power industrial sector. Thus, the estimation results and derived policy advices should be only used at the regional industry level rather than the firm level.

5 The generation costs refer in particular to energy input costs for electricity generation with the subsidy on desulfurization for thermal power sector taking into account. 